\title{
Penggunaan Metode SIIT (Stateless IP/ICMP Translation) Dalam Migrasi IPv4 ke IPv6
}

\section{The Method to Use SIIT (Stateless IP/ICMP Translation) in The Migration from IPv4 to IPv6}

\author{
Kukuh Nugroho ${ }^{1, *}$, Hidni Wafiah ${ }^{2}$, Bongga Arifwidodo ${ }^{3}$ \\ 1,2,3 Program Studi S1 Teknik Telekomunikasi, \\ Fakultas Teknik Telekomunikasi dan Elektro, Institut Teknologi Telkom Purwokerto \\ Jl D.I. Panjaitan no.128, Purwokerto 53147, Jawa Tengah, Indonesia \\ 1,*Penulis korespondensi: kukuh@ittelkom-pwt.ac.id
}

Received on 12-12-2018, accepted on 14-01-2019, published on 28-01-2019

\begin{abstract}
Abstrak
Pengguna Internet yang semakin bertambah mengakibatkan meningkatnya kebutuhan penggunaan alamat IP. Saat ini alokasi alamat IPv4 versi public sudah tidak bisa menampung kebutuhan pengguna Internet. IP versi 6 (IPv6) sebagai IP versi terbaru yang memiliki daya tampung yang lebih banyak dibandingkan dengan IP versi 4 (IPv4) dapat dijadikan sebagai solusi terhadap masalah berkurangnya atau menipisnya alokasi alamat IPv4 versi public. Namun pada implementasinya, penggunaan IPv4 tidak bisa begitusaja digantikan oleh IPv6. Sehingga penggunaan IPv4 akan masih tetap digunakan, walaupun pada saat ini sudah tergantikan oleh IPv6. Diperlukan sebuah solusi agar jaringan yang sudah menggunakan IPv4 dapat terhubung dengan perangkat yang menggunakan IPv6. Pada penelitian ini akan digunakan salah satu metode dalam menghubungkan antara jaringan IPv4 dan IPv6 yaitu SIIT (Stateless IP/ICMP Translation). Parameter performansi yang dianalisa adalah throughput, packet loss dan delay. Konsep jaringan yang digunakan adalah client-server, dimana pada sisi server akan diaktifkan dua layanan untuk diuji yaitu transfer file dan video streaming. Hasil pengukuran pada pengujian layanan transfer file diperoleh data bahwa dengan semakin besar ukuran file yang dipertukarkan, nilai throughput yang dihasilkan juga semakin besar. Begitupula pada pengujian untuk layanan video streaming. Nilai throughput semakin besar dengan memperbesar nilai resolusi video yang digunakan.
\end{abstract}

Keywords: Delay, Metode transisi, SIIT (Stateless IP/ICMP Translation), Throughput

\section{Abstract}

The increasing number of Internet users has resulted in the increasing need for the use of IP addresses. Currently, the public version of IPv4 address allocation cannot accommodate the needs of Internet users. IP version 6 (IPv6) as the latest version of IP which has more capacity than IP version 4 (IPv4) can be used as a solution to the problem of reducing or depleting the public version of IPv4 address allocation. However, in its implementation, the use of IPv4 cannot simply be replaced by IPv6. So that the use of IPv4 will still be used, although at this time it has been replaced by IPv6. A solution is needed so that networks that already 
use IPv4 can connect with devices that use IPv6. In this study, one method of connecting between IPv4 and IPv6 networks will be used, namely SIIT (Stateless IP/ICMP Translation). The analyzed performance parameters are throughput, packet loss, and delay. The network concept used is client-server, where on the server-side two services will be activated to be tested, namely file transfer and video streaming. The measurement results on testing file transfer services obtained data that the larger the size of the files exchanged, the greater the throughput value. Likewise in testing for video streaming services. The throughput value is greater by increasing the value of the video resolution used.

Keywords: Delay, Metode transisi, SIIT (Stateless IP/ICMP Translation), Throughput

\section{Pendahuluan}

IP (Internet Protocol) merupakan protokol yang digunakan sebagai identitas suatu perangkat agar dapat terhubung dengan Internet. IP memiliki dua versi yaitu IP versi 4 (IPv4) dan IP versi 6 (IPv6). Saat ini penggunaan IPv4 masih digunakan oleh perangkat agar bisa terhubung dengan jaringan Internet dan dijadikan sebagai tulang punggung dari infrasuktur internet dan jaringan-jaringan komputer. IPv4 sendiri memiliki pengalamatan berbasis 32 bit yang dapat mengakomodasikan jumlah pengalamatan sampai dengan $2^{32}$ atau sekitar 4,294 x $10^{9}$ [1].

Pertumbuhan pengguna Internet di dunia semakin meningkat, sehingga kebutuhan akan alamat IP juga semakin meningkat. Dari data yang diperoleh dari IANA (Internet Assigned Number Authority) memperlihatkan bahwa alokasi alamat IPv4 sudah tidak mencukupi lagi. Hal ini disebabkan oleh pengguna Internet yang terus meningkat [2]. Diperlukan versi alamat IP terbaru yang memiliki jumlah pengalamatan yang dapat menampung pengguna internet saat ini dan masa datang. IPv6 atau biasa disebut IP next generation merupakan jawaban atas permasalahan keterbatasan IPv4 ditingkat dunia. IPv6 memiliki jumlah bit yang lebih banyak yaitu 128 bit atau sekitar 3,408 1038 alamat IP. Dengan ukuran alamat IP yang lebih besar dimungkinkan dapat mengatasi keterbatasan IP yang sedang dialami [3].

Dengan mengimplementasikan dua mekanisme pengalamatan yang berbeda dalam sebuah jaringan, dapat mengakibatkan antara dua perangkat yang menggunakan mekanisme pengalamatan yang berbeda tidak bisa saling berkomunikasi. Diperlukan sebuah metode atau mekanisme agar antar perangkat dengan mekanisme pengalamatan yang berbeda bisa saling berkomunikasi. SIIT (Stateless IP/ICMP Translation) merupakan salah satu metode yang dapat digunakan untuk mengatasi permasalahan tersebut. Translasi sendiri dapat diartikan sebagai sebuah metode untuk menterjemahkan sebuah data yang datang dari jaringan IPv4 agar bisa terhubung ke dalam jaringan IPv6, begitupula sebaliknya. Selain SIIT, terdapat metode translasi lain yang bisa digunakan, diantaranya adalah SIIT, BIS, BIA dan NAT-PT, namun pada penelitian ini hanya difokuskan pada penggunaan metode translasi SIIT saja. Parameter yang digunakan untuk menguji jaringan diantaranya adalah throughput, delay dan packet loss.

\section{KaJian Pustaka}

Pada penelitian Abdul [4] yang berjudul "Performance Evaluation of Simultaneous Network Configuration Using Dual Stack and Tunnel Transition Techniques: An enterprise Level Analisys" tentang menghubungkan IPv4 dengan IPv6 untuk metode yang digunakan yaitu dual stack dan tunnelling. Dalam penelitian ini bertujuan untuk menganalisis performasi yang dapat dilihat dari parameter yang digunakan yaitu delay. Untuk melakukan implementasi metode dual stack dan tunnelling peneliti menggunakan software simulasi berupa GNS3, Oracle Virtual Box dan juga Wireshark sedangkan untuk perangkat keras yang digunakan yaitu PC dengan spesifikasi Intel Corei3-Corei5, Ram 6Gb, Hard Drive 500Gb dan untuk perangkat network yang digunakan yaitu Router R1 (Cisco 2691), Router R2 (3660), Router R3 (Cisco 3700), PC IPv6 (Windows 7), PC IPv4 (Windows XP) kedua PC yang telah terhubung dengan Oracle Virtual Box. Hasil yang ditujukkan dari percobaan tes koneksi dengan menggunakan metode Dual Stack lebih kecil dengan nilai minimun delay sebesar $0 \mathrm{~ms}$ dan untuk nilai maksimum delay sebesar $176 \mathrm{~ms}$ maka hasil rata-rata delay dari penggunaan metode Dual Stack sebesar $32 \mathrm{~ms}$ sedangkan untuk metode tunnelling memiliki nilai yang lebih besar dengan nilai minimum delay sebesar $12 \mathrm{~ms}$ dan untuk nilai maksimum sebesar $432 \mathrm{~ms}$ maka hasil rata-rata delay dari penggunaan metode tunneling adalah sebesar $109 \mathrm{~ms}$. 
Pada penelitian yang dilakukan oleh Adarsh yang berjudul "Performance Analysis of IPv6 Dual-Protocol Stack and Tunnel Transition" dimana parameter performansi yang digunakan adalah throughput dan layanan yang digunakan adalah berupa pertukaran file antara client dan server. Dalam penelitian ini metode yang digunakan yaitu dual stack, ISATAP tunnel, dan 6to4 tunnel. Hasil penelitian menunjukkan nilai throughput untuk implementasi transfer file dengan menggunakan mekanisme pengalamatan IPv6 lebih besar dari IPv4. Sedangkan untuk perbandingan hasil throughput pada metode dual stack memiliki nilai yang lebih rendah dibandingkan dengan metode 6to4 dan ISATAP. Dari penelitian tersebut dapat disimpulkan bahwa penggunaan metode dual stack memiliki performansi yang lebih baik dibandingkan dengan metode 6to4 dan ISATAP [5].

Hasil penelitian lain yang dilakukan oleh Adira yang berjudul "Performance Evaluation of IPv4/IPv6 Transition Mechanisms", dimana metode transisi yang digunakan adalah ISATAP, 6to4 dan Nat64 [6]. Dalam penelitian tersebut digunakan parameter trhoughput dan OWD (One Way Delay) untuk mengalisa performansi jaringan. Jaringan uji digunakan protokol layer transport UDP dan FTP. Pada penelitian ini menggunakan beberapa system operasi seperti Debian, Windows 7, Windowss 8 dan Windows 10 sedangkan untuk jaringan yang digunakan yaitu jaringan Ethernet dan Fast Ethernet. Hasil penelitian penunjukkan bahwa parameter OWD pada jaringan Ethenet dengan sistem operasi Debian dan metode yang digunakan adalah 6to4 dan ISATAP memiliki nilai performansi jaringan yang sama, sedangkan untuk hasil Nat64 Jool dan Nat64 Tayga memiliki nilai yang serupa sedangkan yang menggunakan sistem operasi Windows 7, 8, dan 10 memiliki nilai yang sama dengan sistem operasi Debian. Hasil uji jairngan pada jaringan Fast Ethernet dengan parameter OWD memiliki hasil yang sama untuk metode 6to4 dan ISATAP sedangkan untuk sistem operasi Debian dan metode yang digunakan NAT64 Jool memiliki nilai yang normal. Pada nilai parameter throughput yang menggunakan jaringan Ethernet pada metode 6to4 dan ISATAP menunjukkan nilai throughput lebih rendah dibandingkan dengan IPv6 sedangkan untuk Nat64 jool dan Tayga memiliki nilai yang sama dalam penilian berdasarkan sistem operasi Debian memiliki nilai yang lebih unggul. Kemudian untuk nilai throughput dalam jaringan Fast Ethenet untuk nilai protokol UDP sama dengan nilai pada jaringan Ethernet dan dari metode tunnel memiliki nilai yang sama. Sedangkan jika dilihat dari performasi sistem operasi yang lebih unggul yaitu Debian [6].

Penelitian lain yang berkaitan dengan metode transisi IPv4 ke IPv6 juga dilakukan oleh Merlie [7]. Metode yang digunakan adalah Dual Statck yang digabungkan dengan jaringan VLAN. Hasil dari pengujian parameter throughput pada pengambilan file data IPv6 dual stack memiliki nilai yang tinggi yaitu sebesar 31.425 Mbps, sedangkan untuk parameter jitter IPv4 dual stack memiliki nilai yang tinggi yaitu $2.33 \mathrm{~ms}$. 


\section{Metode Penelitian}

Dalam melakukan penelitian ini, terdapat beberapa tahapan dan aspek-aspek yang digunakan dalam melakukan penelitian. Pada gambar 1 dibawah merupakan diagram alir dari proses penelitian.

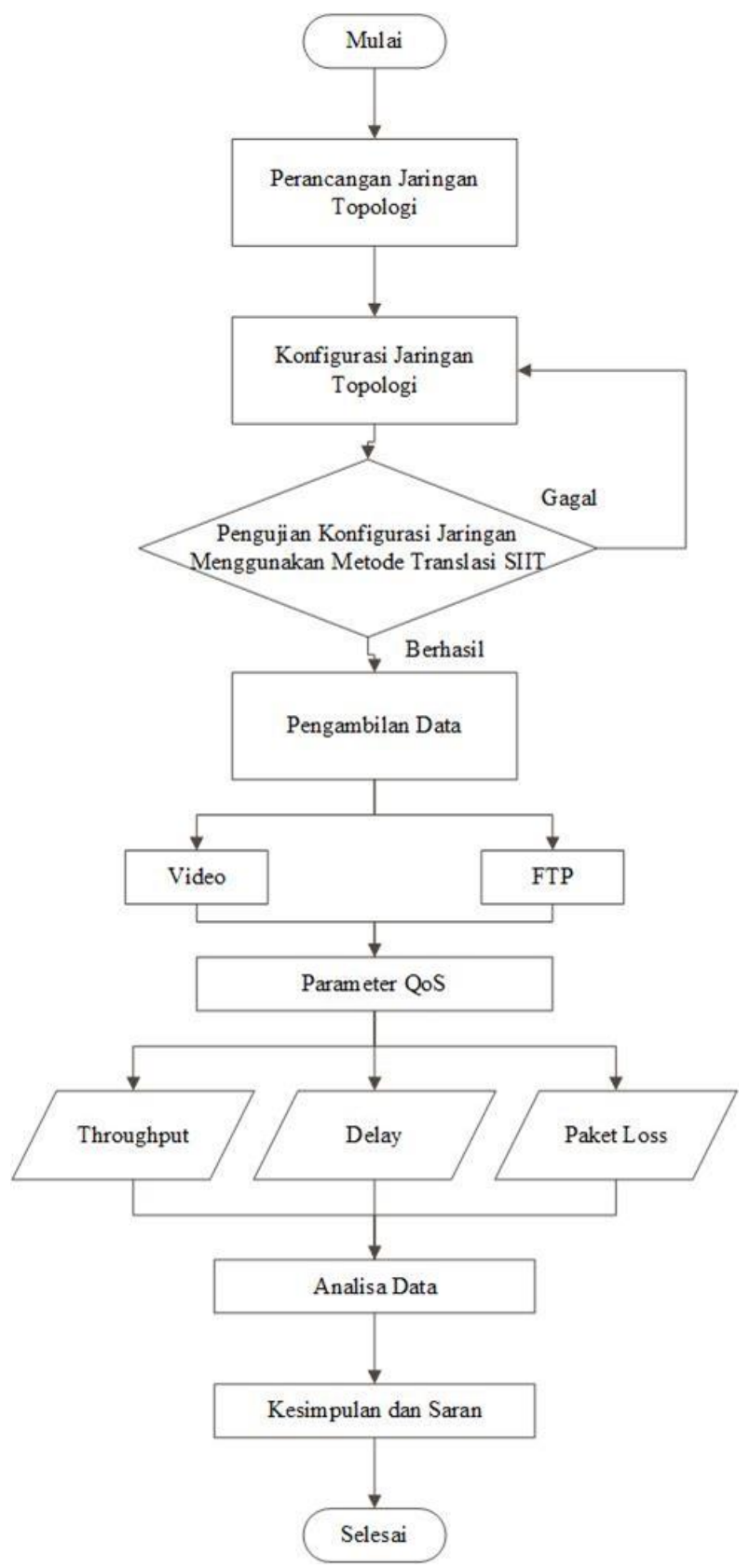

Gambar 1. Alur kerja perancangan jaringan

Dalam penelitian ini hanya menggunakan satu skenario yaitu menggunakan metode translasi SIIT (Stateless IP/ICMP Translastion). Metode translasi SIIT merupakan algoritma dasar yang digunakan sebagai dasar metode translasi [8]. Cara kerja dari metode SIIT yaitu menghilangkan header dari IPv4 menjadi header IPv6 yang tetap bertugas pada layer network karena SIIT hanya melihat dari ID atau tanda pengenal dari masing-masing IP. Dalam komunikasi SIIT terjadi pula pesan antara ICMPv6 dan ICMPv4. Dalam implementasi jaringan ini menggunakan 3 buah perangkat yang berupa dua buah pc sebagai server dan satu pc yang digunakan sebagai translator serta satu laptop digunakan sebagai client dan sistem operasi yang digunakan adalah Ubuntu. 


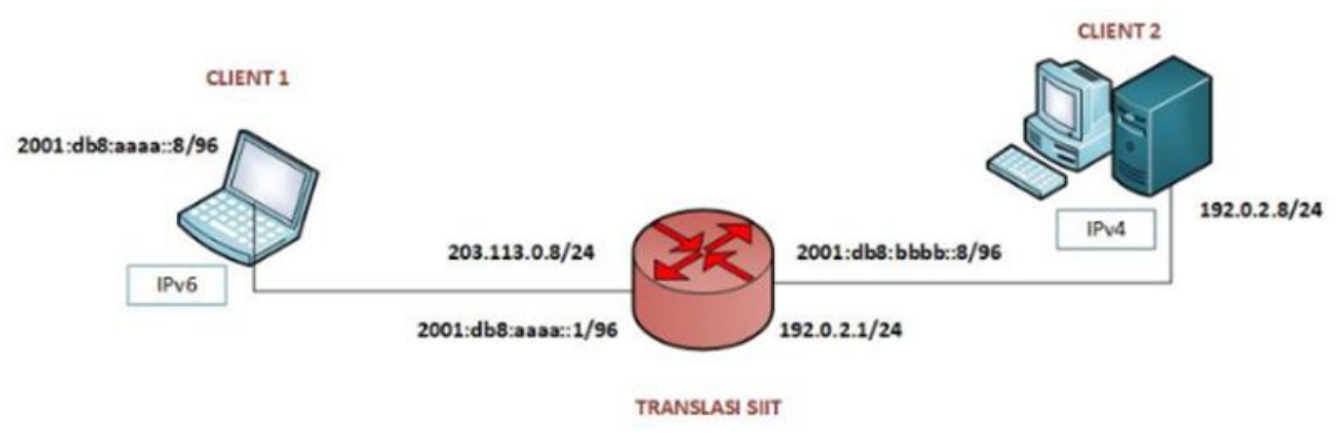

Gambar 2. Implementasi jaringan

Penelitian ini menggunakan topologi jaringan seperti yang terlihat pada Gambar 2 diatas. Topologi jaringan menggunakan satu buah perangkat router yang digunakan sebagai penerapan metode translasi SIIT. Terdapat satu perangkat Laptop yang digunakan sebagai server dan satu buah PC sebagai client yang bertugas untuk menerima data yang telah dikirimkan oleh server. Tahapan awal dari proses konfigurasi jaringan adalah memberikan alamat IP pada masing-masing perangkat dan juga konfigurasi metode translasi SIIT.

Tahapan proses konfigurasi dari masing-masing PC/Laptop yang tersedia dan instalasi server sebagai translator dilakukan dengan cara menginstall module Jool yang berfungsi untuk menjalankan translasi SIIT. Jika semua konfigurasi telah selesai dilakukan pada masing-masing perangkat, kemudian dilakukan tes koneksi (ping) antar PC/Laptop.

Layanan yang diaktifkan pada jaringan adalah berupa transfer data dan video streaming. Pengujian dilakukan pada kedua layanan tersebut dengan menggunakan parameter analisa yaitu throughput, delay dan packet loss. Kemudian dari hasil parameter tersebut akan diolah agar mendapatkan hasil performasi dari metode translasi SIIT. Dalam proses pengambilan data menggunakan software wireshark yang berfungsi sebagai network analyzer pada sisi penerima dan pengirim selama proses pengiriman data.

\section{A. Perancangan Metode Translasi SIIT}

Fungsi router dalam topologi jaringan pada Gambar 2 digantikan oleh sebuah komputer. Proses translasi sebagai fungsi utama dari skenario pengujian sistem sepenuhnya dilakukan oleh komputer tersebut. Komputer server akan dijadikan sebagai mesin translasi antara jaringan IPv4 dan IPv6. Pada pengujian sistem kali ini digunakan software Jool yang berjalan pada sistem operasi Ubuntu. Berikut adalah tahapan dalam menginstall software Jool sebagai aplikasi mesin translasi:

Perintah awal yang digunakana adalah / bin/uname $-r$. Perintah tersebut digunakan untuk melihat apakah komputer server support software Jool ataukah tidak.

Tahap berikutnya adalah menginstall paket-an modul pada software Jool. Perintah yang digunakan adalah apt-get install build-essential.

langkah terahir untuk menginstall dkms dengan memasukkan perintah apt-get install dkms kemudian masukkan perintah unzip Jool-<version>.zip enter lalu dkms install Jool-<version>.

\section{B. Proses Pengambilan Data}

Setelah semua tahap konfigurasi sudah sesuai dengan skenario dan topologi yang telah dibuat, maka dibutuhkan pengujian untuk menghasilkan data yang nantinya dianalisa untuk mengetahui performansi jaringan. Pada penelitian ini proses pengambilan data menggunakan layanan yang berbeda yaitu video streaming dan transfer data. Nilai parameter yang akan diukur untuk selanjutnya akan dianalisa yaitu throughput, delay dan packet loss. Hasil dari pengukuran akan dianalisa tingkat baik atau buruknya performansi jaringan dengan menggunakan acuan standarisasi yang dikeluarkan oleh TIPHON [9]. 
Tabel 1. Standarisasi TIPHON untuk delay

\begin{tabular}{|c|c|}
\hline Kategori & Delay $(\mathrm{ms})$ \\
\hline Sangat bagus & $<150$ \\
\hline Bagus & $150 \mathrm{~s} / \mathrm{d} 300$ \\
\hline Sedang & $300 \mathrm{~s} / \mathrm{d} 450$ \\
\hline Buruk & $>450$ \\
\hline
\end{tabular}

Tabel 2. Standarisasi TIPHON untuk packet loss

\begin{tabular}{|c|c|}
\hline Kategori & Delay (\%) \\
\hline Sangat bagus & 0 \\
\hline Bagus & 3 \\
\hline Sedang & 15 \\
\hline Buruk & 25 \\
\hline
\end{tabular}

Dalam proses pengambilan data menggunakan aplikasi wireshark yang dipasang pada sisi PC client selama proses pengiriman data. Fungsi dari proses pengambilan data ini adalah untuk mengetahui performasi yang dihasilkan dari proses translasi SIIT. Rancangan ukuran dari resolusi video dan ukuran data yang dipertukarkan antara client dan server dapat dilihat pada keterangan tabel 3 berikut:

Tabel 3. Rancangan skenario migrasi menggunakan metode SIIT

\begin{tabular}{|c|c|c|c|}
\hline No & Tipe Layanan & Resolusi (P) & Parameter \\
\hline \multirow{5}{*}{1} & \multirow{5}{*}{ Video } & 240 & \multirow{5}{*}{$\begin{array}{c}\text { Throughput, Delay dan } \\
\text { Packet loss. }\end{array}$} \\
\hline & & 360 & \\
\hline & & 480 & \\
\hline & & 720 & \\
\hline & & 1080 & \\
\hline No & Tipe Layanan & Ukuran Data (Mb) & Parameter \\
\hline \multirow{5}{*}{2} & \multirow{5}{*}{ Data } & 5 & \multirow{5}{*}{$\begin{array}{c}\text { Throughput, Delay dan } \\
\text { Packet loss. }\end{array}$} \\
\hline & & 10 & \\
\hline & & 15 & \\
\hline & & 25 & \\
\hline & & 50 & \\
\hline
\end{tabular}

Layanan yang digunakan untuk proses uji performansi jaringan adalah video streaming dan layanan transfer data. Ukuran file video dibuat berubah menggunakan ukuran resolusi yang bervariasi. Tabel 3 di atas menjelaskan ukuran resolusi dari file video yang digunakan, dimulai dari 240 P, 360 P, 480 P, 720 P, dan 1080 P. Dengan mengubah ukuran resolusi video diharapkan dapat menggambarkan performansi jaringan. Begitupula untuk ukuran data. Perubahan ukuran data dimulai dari $5 \mathrm{MB}, 10 \mathrm{MB}$, sampai $50 \mathrm{MB}$. Pengukuran jaringan digunakan software Wireshark. Dalam proses pengambilan data dilakukan simulasi pengiriman data dengan IP 203.113.0.8 yang bertugas untuk mengirimkan data dan IP 192.0.2.8 yang bertugas untuk menerima data. Software wireshark pada sisi PC dapat diamati ketika terdapat data yang dipertukarkan oleh PC tersebut. Pengambilan data dapat dilihat dari sisi PC server dimana data yang dikirimkan dengan ukuran yang bervariasi dan kemudian dari sisi PC client dapat dilihat performansi jaringan dari parameter delay dan throughput dengan menggunakan bantuan software Wireshark. Proses pengambilan data dilakukan sebanyak 30 kali hal ini berlaku untuk semua tipe data mulai dari layanan video streaming sampai dengan layanan transfer data. 


\section{Hasil dan Pembahasan}

Penelitian ini menggunakan perangkat langsung dengan system operasi linux ubuntu desktop dan untuk pengambilan data menggunakan wireshark. Penelitian ini menggunakan protokol TCP (Transmision Control Protocol) dan UDP (User Datagram Protocol) dan layanan data yang digunakan yaitu transfer data dan video streaming.

\section{Analisis Throughput}

Throughput merupakan suatu ukuran keberhasilan secara aktual dalam pengiriman paket data pada jaringan komputer oleh suatu perangkat, yang dapat dilihat dari berapa banyak paket data (bit) yang berhasil dalam kurun waktu satu detik. Nilai dari throughput diukur dengan satuan bps (bit per second) [10]. Throughput dapat dilihat dari hasil waktu pengamatan dan ukuran data yang terdapat pada aplikasi wireshark.

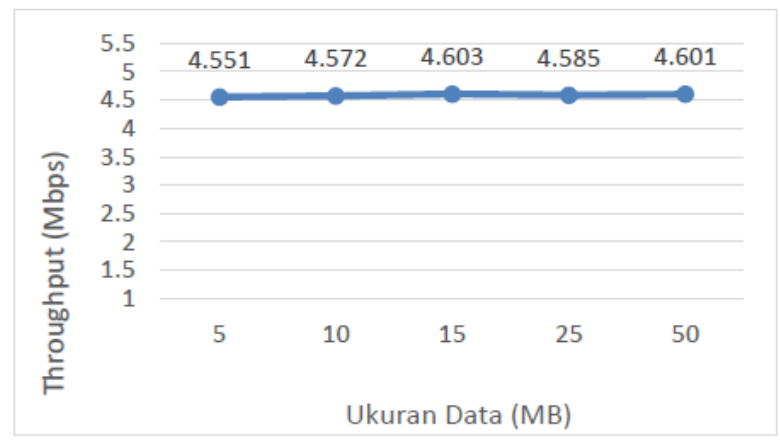

Gambar 3. Hasil throughput pada transfer data

Pada Gambar 3 dapat dilihat hasil throughput ukuran 5 MB dengan nilai 4,551 Mbps, kemudian untuk ukuran data $15 \mathrm{MB}$ memiliki hasil nilai sebesar 4,603 Mbps dan untuk ukuran $50 \mathrm{MB}$ memiliki hasil nilai sebesar 4,601 Mbps. Perbedaan hasil throughput pada ukuran data 15 MB memiliki nilai yang lebih besar dibandingkan dengan ukuran data $5 \mathrm{MB}$ dan $50 \mathrm{MB}$, hal ini disebabkan dari 30 pengambilan data terdapat beberapa data yang memiliki nilai yang berbeda sehingga dapat mempengaruhi hasil throughput pada penelitian ini. Berdasarkan throughput yang dihasilkan pada penelitian ini, apabila ukuran data yang digunakan semakin besar maka nilai throughput yang dihasilkan juga akan semakin meningkat akan tetapi tidak terlalu signifikan.

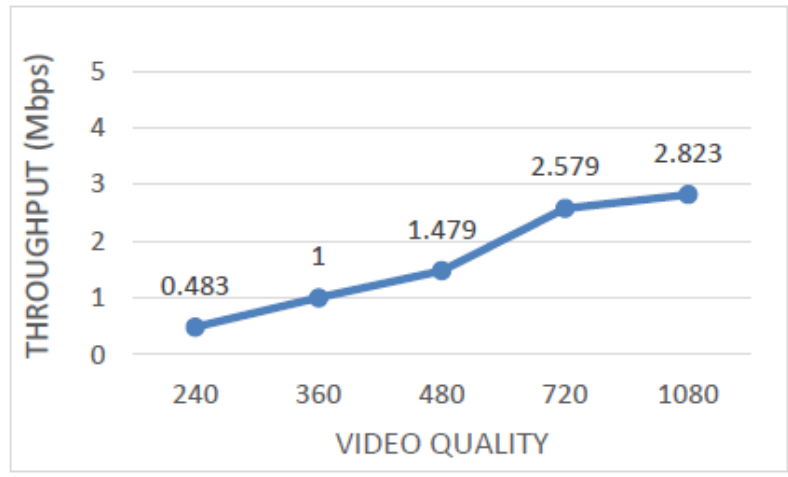

Gambar 4. Grafik throughput pada layanan video streaming

Pada Gambar 4 merupakan hasil throughput untuk layanan video streaming yang dimulai dari resolusi 240p memiliki hasil 0.483 mbps kemudian untuk hasil throughput dalam resolusi 1080p memiliki hasil 2.823 mbps. Kemudian hasil dari pengukuran throughput yang ditunjukan pada gambar 4 didapatkan hasil apabila resolusi sebuah video semakin tinggi maka nilai throughput yang didapatkan juga akan semakin tinggi. 
Pada hasil throughput untuk layanan file sharing dengan layanan video streaming memiliki nilai yang berbeda jika dilihat dari sisi ukuran data yang digunakan. Untuk layanan file sharing ukuran data yang digunakan sekisar 5 sampai dengan $50 \mathrm{MB}$ sedangkan untuk ukuran data yang digunakan pada layanan video streaming ukuran data yang digunakan sekisar 2 sampai dengan $24 \mathrm{MB}$. Sehingga hasil throughput yang didapatkan pada layanan file sharing lebih besar dibandingkan dengan layanan video streaming.

\section{Analisis Packet Loss}

Packet loss merupakan suatu kegagalan atau sebuah paket yang tidak sampai dengan sempurna pada jaringan komputer selama proses pertukaran data [11]. Rumus yang digunakan untuk perhitungan packet loss didapatkan dari jumlah paket yang dikirim dikurangi dengan jumlah paket yang diterima dan untuk satuan dari packet loss yaitu (\%).

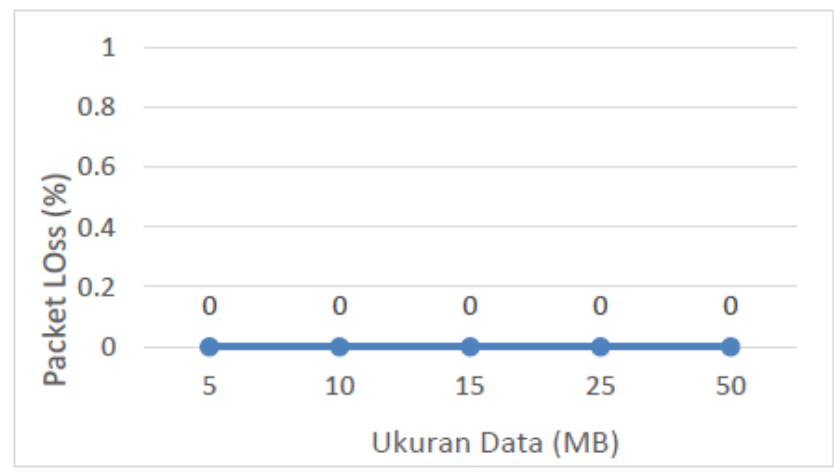

Gambar 5. Grafik packet loss pada layanan file sharing

Berdasarkan hasil yang didapatkan dari Gambar 5 jumlah packet loss untuk layanan transfer data tidak terdapat nilai packet loss. Hasil pengujian ini berarti untuk seluruh paket yang dikirimkan pada jaringan ini dapat terkirim dengan sempurna dan tidak ada paket yang hilang mulai dari ukuran data 5Mb sampai dengan $50 \mathrm{Mb}$. Hasil pengujian ini juga sesuai dengan standarisasi yang dikeluarkan oleh TIPHON (Telecomunication and Internet Protocol Harmonization Over Network) karena memiliki nilai kurang dari $150 \mathrm{~ms}$.

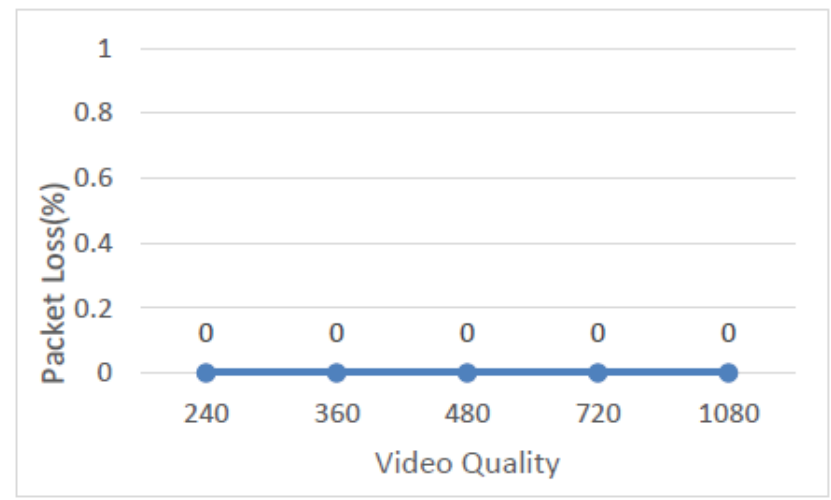

Gambar 6. Grafik packet loss pada layanan video streaming

Pada pengujian packet loss untuk layanan video streaming dapat dilihat pada gambar 6. Grafik tersebut menunjukan tidak adanya nilai pada packet loss dari resolusi yang paling rendah sampai dengan resolusi yang paling tinggi. Hal ini berarti tidak didapatkan paket yang hilang atau rusak dalam proses video streaming sehingga gambar yang dihasilkan dalam kualitas yang baik. Dari hasil data packet loss pada layanan transfer data dan layanan video streaming memiliki nilai yang sama yaitu tidak memiliki packet loss. Hasil packet loss dari gambar 6 lebih disebabkan kareana protokol yang digunakan untuk layanan file sharing adalah TCP, yang memiliki sifat connection oriented yang berarti bahwa pada saat pengiriman 
paket adanya pengecekan paket yang akan dikirim ke penerima, sehingga dapat memastikan tidak adanya paket yang hilang atau rusak. Sedangkan untuk layanan video streaming protokol yang digunakan yaitu UDP yang memiliki sifat connectionless yang berarti pada protokol ini tidak adanya pengecekan data sebelum dikirim ke tujuan.

\section{Analisis Delay}

Delay merupakan sebuah total waktu yang dibutuhkan sebuah paket untuk menempuh jarak dari pengiriman sampai dengan ke tujuan/penerima [11].

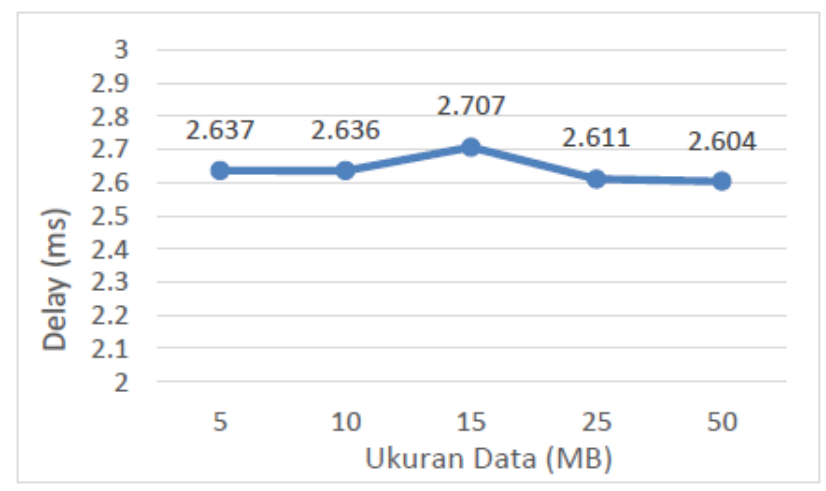

Gambar 7. Grafik delay pada layanan file sharing

Pada gambar 7 menampilkan grafik delay dari layanan transfer data dengan menggunakan ukuran file yang berbeda-beda. Dari hasil grafik delay menunjukan bahwa pada ukuran data $5 \mathrm{Mb}$ memiliki nilai delay sebesar $2.63 \mathrm{~ms}$, sedangkan untuk ukuran data $15 \mathrm{Mb}$ memiliki nilai delay $2.70 \mathrm{~ms}$. Pada ukuran data 50 $\mathrm{Mb}$ memiliki nilai delay $2.60 \mathrm{~ms}$. Perubahan nilai delay pada grafik 7 dipengaruhi dari nilai throughput, dimana jika hasil throughput semakin meningkat maka hasil delay yang didapatkan akan semakin menurun dan begitu pula sebaliknya. Hasil delay untuk layanan file sharing berdasarkan keterangan grafik pada gambar 7 diatas masih sesuai standar TIPHON.

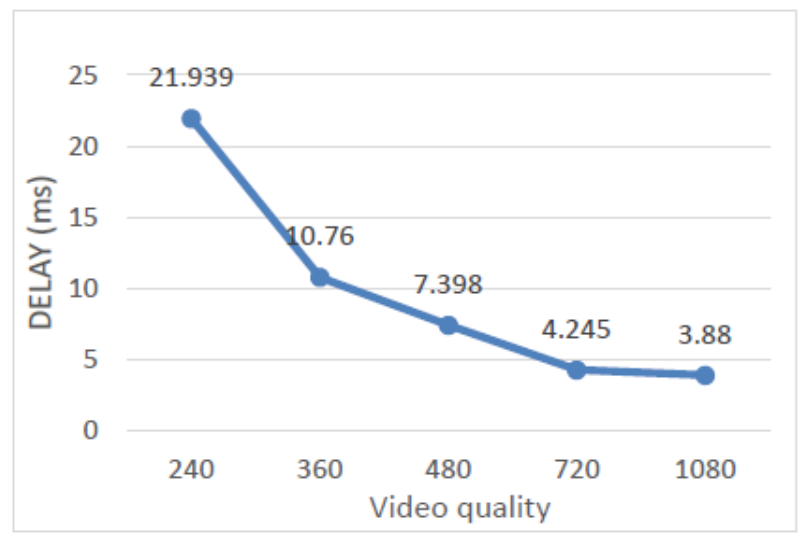

Gambar 8. Grafik delay pada layanan video streaming

Hasil delay pada pengujian layanan video streaming dapat dilihat pada Gambar 8 yang menunjukan hasil pada resolusi video 240p memiliki nilai delay lebih tinggi yaitu dengan nilai $21.93 \mathrm{~ms}$ dibandingkan dengan resolusi video 1080p yang memiliki nilai delay $3.88 \mathrm{~ms}$. Hasil nilai delay tersebut dipengaruhi oleh jumlah frame rate dan bit rate pada video yang digunakan pada pengujian jaringan. Nilai frame rate yang kecil dibandingkan dengan ukuran data dapat mempengaruhi nilai delay. Sedangkan pengaruh nilai bit rate terhadap nilai delay adalah semakin besar nilai bit rate maka akan memperkecil nilai delay yang didapatkan. Jika semakin kecil nilai bit rate maka akan semakin besar pula nilai delay yang didapatkan. Dari hasil gambar 8 menunjukan delay terbesar pada resolusi video 240p yaitu sebesar $21.93 \mathrm{~ms}$ dimana menurut standar TIPHON masih dikatakan baik karena kurang dari $150 \mathrm{~ms}$. 


\section{KESIMPULAN}

Berdasarkan hasil analisa yang dilakukan pada penelitian performasi metode translasi SIIT dalam migrasi IPv4 ke IPv6 maka didapatkan bahwa hasil throughput pada layanan transfer data dengan ukuran file 50 MB sebesar 4.60 Mbps, sedangkan pada layanan video streaming dengan resolusi 1080p memiliki nilai throughput sebesar 2.83 Mbps. Pada layanan data diperoleh hasil bahwa semakin meningkatnya ukuran sebuah data maka nilai throughput juga akan semakin meningkat. Sedangkan pada pengujian delay memperlihatkan bahwa untuk layanan transfer data menunjukan nilai sebesar 2.63 MB untuk ukuran data 5 sedangkan untuk ukuran data $50 \mathrm{MB}$ memiliki nilai sebesar $2.60 \mathrm{~ms}$. Sedangkan pada hasil delay pada layanan video streaming dengan resolusi 240 lebih tinggi sebesar $21.93 \mathrm{~ms}$ sedangkan untuk resolusi 1080 memiliki delay yang rendah sebesar $3.88 \mathrm{~ms}$.

\section{Daftar Pustaka}

[1] R. Rafiudin, IPv6 Addressing, Jakarta: Kelompok Gramedia, 2005

[2] H. Geoff, "A Look Back at word of IP Addressing in 2017: What Changed and What to Expect," circleid, 25 Januari 2018. [Online]. Available: http://www.circleid.com/posts/20180125_a_look_back_at_ip_addressing_2017_ what_changed/. [Accessed 11 July 2018].

[3] R. H. Abdul Basit, "Performance Evaluation of Simultaneous Network Configuration Using Dual Stack and Tunnel Transition Techniques: An enterprise Level Analisys," IASE, pp. Pages 102-109, 2017.

[4] H. C. Adarsh Misra, "Performance Analysis of IPv6 Dual-Protocol Stack and Tunnel Transition," International Journal of Science, Engineering and Technology Research (IJSETR), vol. Vol 5, no. Issue 5, 2016.

[5] F. S. E. G. Adira Quintero, "Performance Evaluation of IPv4/IPv6 Transition Mechanisms," I.J.Computer Network and Information Secuarity, vol. Vol 2, pp. Pages 1-14, 2016.

[6] S. R. M. S. Merlie Anita, "Analisis dan Perancangan Jaringan Dual Stack Sebagai Metode Transisi IPv4 ke IPv6," Jurnal JARKOM, vol. Vol.1 No.2, 2014.

[7] E. Nordmark, RFC 2765 Stateless IP/ICMP Translation (SIIT), USA: RFC, 2000.

[8] TIPHON, "TIPHON Release 3; Technology Compliance Specification; Part 5: Quality of Serice (Qos) meansurement methodologies," ETSI 101 329-5 , vol. 1.1.1, 2000.

[9] I. Sofana, Cisco CCNA \& Jaringan Komputer, Bandung: Informatikan Bandung, 2009.

[10] I. P. A. E. Pratama, Handbook Jaringan Komputer, Bandung: Informatika Bandung, 2015. 